\title{
Thoracic Extra Cardiac Complications Detected in Patients after GABG at Multidetectorcomputed Tomography Coronary Angiography
}

\author{
Hesham M. Farouk, Ibrahim M. Helmy, Ahmed M. shalaan, Mona M. Rewisha
}

Department of Radiodiagnosis, Faculty of Medicine Benha University, Egypt.

Correspondence to: Mona M. Rewisha, Department of Radiodiagnosis, Faculty of Medicine Benha University, Egypt.

Email:

monamadgy2019@gmail.com

Received: 13 November 2019

Accepted: 17 October 2021

\begin{abstract}
Background: Postoperative complications significantly contribute to prolonged hospitalization and intensive care unit (ICU) stay following CABG surgery. Aim: To demonstrate the role and limitations of multi-detector computed tomography angiography in the accurate detection and follow up of thoracic extra-cardiac complications of CABG. Methods: Patients undergone ECG gated MDCT coronary angiography in CT unit in radiology department of national heart institute will be analyzed from PACS (syngo.via acquisition system) and we will include patients with observing thoracic extra-cardiac complications post CABAG. Results: 20 patients aged from 37 to 85 with $60.55 \pm 10.94$ (mean \pm SD) of which $80.0 \%$ is male patient. All the studied group suffer from chest pain and about two thirds $(70.0 \%)$ of them suffers from respiratory distress, while only $20.0 \%$ complains of fever, $20.0 \%$ complains dry cough and only $10.0 \%$ suffers from productive cough. Redu, pleural effusion and sternal diastasis occurs
\end{abstract} among $20 \%$ of cases, pericardial hematoma in $15.0 \%$ and each of sternal suture artefact and pneumonia constitute $10.0 \%$ of them. Each of sternal mediastinal infection, SCA thrombus, surgical emphysema, pneumothorax, retrosternal collection and pericardial effusion represents $5.0 \%$ of cases. Conclusion: Redu, pleural effusion and sternal diastasis were the commonest complications as occurred among $20 \%$ of cases, followed by pericardial hematoma in $15.0 \%$ and each of sternal suture artefact and pneumonia constitute $10.0 \%$ of them

Key words: Thoracic complications; GABG; multidetector computed tomography; coronary angiography 


\section{Introduction}

Coronary artery bypass grafting (CABG) process for coronary revascularization is the primary treatment strategy for many coronary lesions currently. Complications such as respiratory dysfunction, atelectasis, pneumonia, and pleural effusion are common due to the opening of the thoracic cage and the direct effects of the cardio pulmonary bypass in patients undergoing CABG (1). Although the mortality and morbidity rates of CABG vary in different series, respiratory failure is an important cause in all the series (2).

Despite many advances in perioperative care, post-operative pulmonary complications (PPCs) still remain the leading cause of morbidity and death after adult cardiac surgery (3). PPCs are associated with increased length of hospital stay and these have a great influence on health care cost in cardiac surgery patients (4).

Complications can be broadly divided into catastrophic events, such as death and stroke, or less serious complications, such as pulmonary, renal, or sternal wound complications (5).

Postoperative pulmonary complications are the most frequent and significant contributor to morbidity, mortality, and costs associated with hospitalization. Interestingly, despite the prevalence of these complications in cardiac surgical patients, recognition, diagnosis, and management of this problem vary widely (6)

Postoperative complications significantly contribute to prolonged hospitalization and intensive care unit (ICU) stay following CABG surgery. Despite numerous advances in anesthesia, surgical techniques, and postoperative care, postoperative pulmonary complications (PPCs) still account for major CABG surgery postoperative morbidity (7).

\section{Aim of the study}

To demonstrate the role and limitations of multi-detector computed tomography angiography in the accurate detection and follow up of thoracic extra-cardiac complications of CABG.

\section{Patients and methods}

This descriptive observational study was carried out in radiology Department, Benha university Hospital. During the period from January 2019 to October 2019.

Twenty patients will be included in this study. Patients undergone ECG gated MDCT coronary angiography in CT unit in 
radiology department of national heart institute will be analyzed from PACS (syngo.via acquisition system) and we will include patients with observing thoracic extra-cardiac complications post CABAG.

Inclusion criteria: (Post-CABAG) and (Mid Cap) patient shows signs of extra-cardiac complications (fever, dyspnea, cough, unhealthy scar...)

Exclusion criteria: Patients with impaired renal function; Patients that have allergy to contrast; Arrhythmias; Ejection fraction less than $30 \%$.

All studied participants were subjected to:

Patient Preparation: The heart rate was evaluated before the examination. The examination was done if the heart rate is below 65 beats per minute. Patients with heart rates above 65 beats per minute were given cardio-selective beta-blocker; 50/100 $\mathrm{mg}$ of Metoprolol or Atenolol orally 1 hour before the study to obtain a stable low heart rate, provided that contra-indications to $\beta$ blockers are excluded. If the heart rate was still above 65 beats per minutes, the examination was postponed to another setting. Temporary antispasmodic for coronary spasm. To evaluate patients ability of breath-withholding for relatively long time; they were required to perform a deep inspiration and to continue to hold their breath without pushing (i.e., Valsalva maneuver). During this trial, the patient was observed for compliance and the ECG for significant changes.

Contrast Material: A bolus of $120 \mathrm{ml}$ of water soluble non-ionic contrast (Omnipaque $\quad 370 \quad \mathrm{mg} \quad$ Daiichi Pharmaceutical,Tokyo,Japan), was injected through 18 gauge cannula into an upper limb veFrein (right antecubital vein in all our cases to reduce left sided artifacts) with a flow rate of 5 to $5.5 \mathrm{~mL} / \mathrm{sec}$. This injection was automatically followed by injection of about 40-50 $\mathrm{cc}$ of saline at a flow rate of 5 $\mathrm{ml} / \mathrm{sec}$ using a programmed dual head power injector pump (MedRad; USA) to maintain good opacification of the coronary vessels and the grafts with wash out of contrast material from the SVC and right side of the heart that may cause artifacts.

Reconstruction. The data sets are reconstructed (with a slice thickness of $0.625 \mathrm{~mm}$ and $0.4 \mathrm{~mm}$ increments) during the mid to end diastolic phase, $45-75 \%$ of the $\mathrm{R}-\mathrm{R}$ interval. If image quality in this data set is not being optimal, additional reconstructions (35-85\%) is performed and the data sets with optimal images will be chosen for further evaluation. 
All acquired data is transferred to separate computer workstation. Depending on vessel morphology and quality of the MDCT data sets, different post processing techniques such as maximum- intensity projection (MIP), curved multiplanar reconstruction (CPR) and volume rendering (VR) are applied to assess the origin and course of the coronary arteries. We use an upper limit of heart rate of 70 beat per minute.

Padding of the tube-on time is used to allow the reconstruction to adapt to minor heart rate variation. Padding is ranged from 40 to 80 msc.

Dose-length-product (DLP) is recorded from the CT scanner for each patient. The effective radiation dose (E) in $\mathrm{msv}$ is calculated using the formula $E=D L P x K$. The $\mathrm{k}$ is the conversion factor and is equal to 0.017. This $\mathrm{k}$ value is considered applicable for chest and cardiac scans.

Approval will be obtained from Benha University Institutional Review Board (IRB).

\section{Statistical analysis}

Data collected throughout history, basic clinical examination, laboratory investigations and outcome measures coded, entered and analyzed using Microsoft Excel software. Data were then imported into Statistical Package for the Social Sciences (SPSS version 20.0) (Statistical Package for the Social Sciences) software for analysis. According to the type of data qualitative represent as number and percentage, quantitative continues group represent by mean $\pm \mathrm{SD}$, the following tests were used to test differences for significance; Difference and association of qualitative variable by Chi square test (X2). Differences between quantitative independent groups by $t$ test or Mann Whitney, paired by paired t . P value was set at $<0.05$ for significant results \& $<0.001$ for high significant result.

\section{Results}

This study include 20 patients aged from 37 to 85 with $60.55 \pm 10.94$ (mean \pm SD) of which $80.0 \%$ is male patient.

Table 1 demonstrate the chief complaints of patients. All the studied group suffer from chest pain and about two thirds (70.0\%) of them suffers from respiratory distress, while only $20.0 \%$ complains of fever, $20.0 \%$ complains dry cough and only $10.0 \%$ suffers from productive cough.

Table 2 and figure $1 \& 2$ outline non-graft complications of the studied group. Redu, pleural effusion and sternal diastasis occurs 
among $20 \%$ of cases, pericardial hematoma in $15.0 \%$ and each of sternal suture artefact and pneumonia constitute $10.0 \%$ of them. Each of sternal mediastinal infection, SCA thrombus, surgical emphysema, pneumothorax, retrosternal collection and pericardial effusion represents $5.0 \%$ of cases.

Table 1: Distribution of the studied group according to patient complaints.

\begin{tabular}{lll}
\hline Patient Complaint & No & $\%$ \\
\hline Chest pain & & \\
Yes & 20 & 100 \\
No & 0 & 0.0 \\
Resp distress & 14 & 70.0 \\
Yes & 6 & 30.0 \\
No & & \\
Fever & 4 & 20.0 \\
Yes & 16 & 80.0 \\
No & & \\
Dry cough & 4 & 20.0 \\
Yes & 16 & 80.0 \\
No & & \\
Productive cough & 2 & 10.0 \\
Yes & 18 & 90.0 \\
No &
\end{tabular}

Table 2: Distribution of the studied group according to non-graft complications.

\begin{tabular}{lllll}
\hline $\begin{array}{l}\text { Non-graft } \\
\text { complications }\end{array}$ & related & Yes & & No \\
& No & $\%$ & No & $\%$ \\
\hline Redu & 4 & 20.0 & 16 & 80.0 \\
Sternal suture artifact & 2 & 10.0 & 18 & 90.0 \\
Pleural effusion & 4 & 20.0 & 16 & 80.0 \\
Pneumonia & 2 & 10.0 & 18 & 90.0 \\
Pericardial hematoma & 3 & 15.0 & 17 & 85.0 \\
Sternal mediastinal infection & 1 & 5.0 & 19 & 95.0 \\
Sternal mediastinal diastasis & 4 & 20.0 & 16 & 80.0 \\
SCA thrombus & 1 & 5.0 & 19 & 95.0 \\
Surgical emphysema & 1 & 5.0 & 19 & 95.0 \\
Pneumothorax & 1 & 5.0 & 19 & 95.0 \\
Retrosternal collection & 1 & 5.0 & 19 & 95.0 \\
Pericardial effusion & 1 & 5.0 & 19 & 95.0 \\
\hline
\end{tabular}




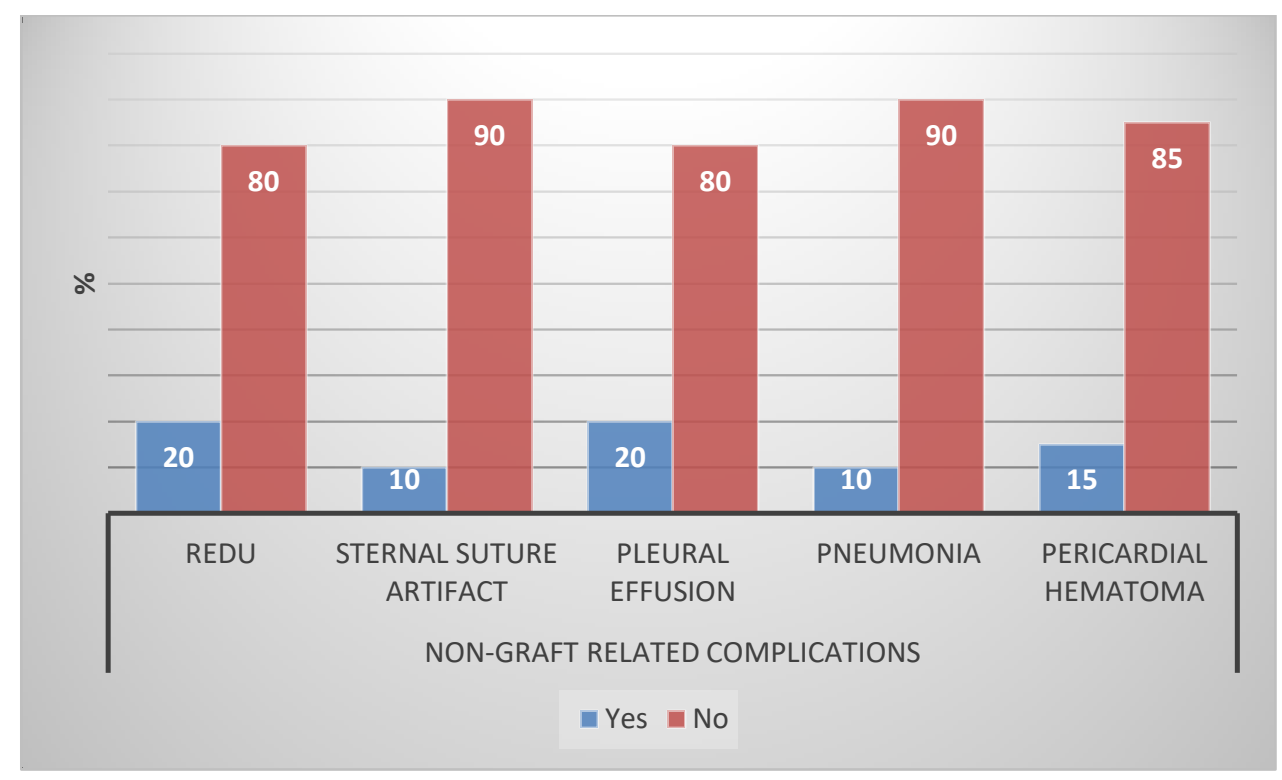

Figure (1): Some of non-graft complications of the studied group.

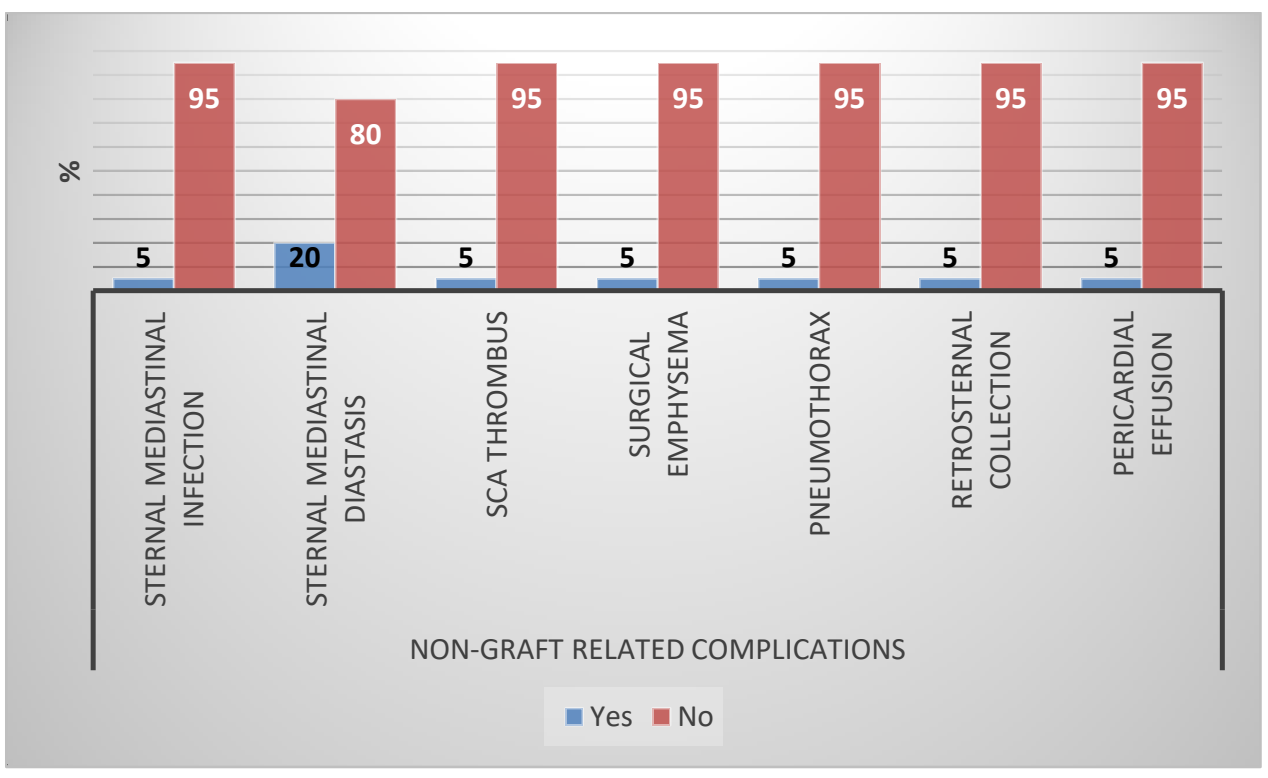

Figure (2): Other non-graft complications of the studied group. 


\section{Discussion}

Our study included 20 patients aged from 37 to 85 with $60.55 \pm 10.94$ (mean \pm SD) of which $80.0 \%$ is male patient and this is consistent with the retrospective national database analysis Settings: United States hospitals. A weighted sample of 1,910,236 patient sunder going CABG surgery identified from the National (Nationwide) Inpatient sample from 2008 to 2012 by (8) and reported that Patients With Any Complications $(\mathrm{n}=735,441)$ median age was $67(60-75) \quad \mathrm{p}<0.001$ and $28.9 \%$ were females.

Regarding non-graft complications we found that Redu, pleural effusion and sternal diastasis occurs among $20 \%$ of cases, pericardial hematoma in $15.0 \%$ and each of sternal suture artefact and pneumonia constitute $10.0 \%$ of them. Each of sternal mediastinal infection, SCA thrombus, surgical emphysema, pneumothorax, retrosternal collection and pericardial effusion represents $5.0 \%$ of cases. On the contrary (8) found that overall, $38.5 \%$ of patients experience danin-hospital complication, with $6.3 \%$ of patients experiencing more than 1 complication during their hospital stay. Postoperative hemorrhage complications were the most frequent adverse outcomes (30.4\%),followed by cardiac $(11.34 \%)$ and respiratory complications $(2.3 \%)$. While no uniform trend was found for neurologic complications during the study period, the rates of in-hospital cardiac ,respiratory, and infectious complications decreased significantly from 2008 to 2012 ( $p<0.001)$.

It is widely known that there is an impairment in pulmonary function immediately after CABG surgery (9) and persistent postoperative hypoxemia has been described as its most prevalent manifestation, even in the absence of preoperative pulmonary disease (10). In the study of (1), observed an important reduction in $\mathrm{PaO} 2 / \mathrm{FiO} 2$ ratio during surgery, reaching its nadir immediately after $\mathrm{CPB}$, partially recovering after $48 \mathrm{~h}$. In previous investigations, atelectasis has been consistently associated with worsening of gas exchanges after $\mathrm{CPB}$ in experimental or clinical contexts. In an animal model, Magnusson (11), found extensive atelectasis formation after $\mathrm{CPB}$, accounting for $35 \%$ of the total lung area observed in a juxtadiaphragmatic CT section, while control submitted to general anesthesia and sternotomy presented only a small amount of atelectasis (approximately 4\%). These investigators reported a good correlation 
between the extension of lung density and shunt fraction $(\mathrm{R} 2=0.67)$. One researcher (12) observed a significant correlation $(\mathrm{r}=$ 0.875 ) between the size of dense lung areas computed by $\mathrm{CT}$ and the intrapulmonary shunt in 11 patients with impaired respiratory function after coronary artery revascularization surgery. Conversely, another researcher (13) did not correlate the extension of collapsed lung parenchyma represented in patients submitted to $\mathrm{CABG}$ to the magnitude of the shunt.

Possibly, other factors are associated with postoperative worsening of gas exchanges observed in the first postoperative day in addition to the perfusion of non-aerated lung areas: 1) a relative increase in the contribution of poorly aerated parenchyma (V/Q mismatch) to hypoxemia; 2) a reduction in normally aerated parenchyma, and 3) an increase in extravascular lung water (1).

\section{Conclusion}

Thoracic extra cardiac complications are common after coronary artery bypass grafting. Redu, pleural effusion and sternal diastasis were the commonest complications as occurred among $20 \%$ of cases, followed by pericardial hematoma in $15.0 \%$ and each of sternal suture artefact and pneumonia

constitute $10.0 \%$ of them. Then sternal mediastinal infection, SCA thrombus, surgical emphysema, pneumothorax, retrosternal collection and pericardial effusion represent $5.0 \%$ of cases. A good understanding of the most common respiratory complication allows for an earlier identification of complications, prompt intervention and a reduced adverse effect on patients.

\section{Recommendations}

Follow up of patients after CABG for early detection of any complications especially thoracic extra cardiac complications; Give attention to patient complaint after $\mathrm{CABG}$ like chest pain, fever, cough either dry or productive as it may be indicative of a serious complication; Detection of small number of significant or major findings and detection mostly of non-significant or minor findings in cardiac MSCT should not be taken lightly and follow up patient regularly; Give patient instructions to early seek medical advice if any symptom occur; search for other serious complications like : pulmonary embolism; Other large prospective studies with more sample size should be done to confirm our results.

\section{References}


1. Rodrigues RR, Sawada AY, Rouby J-J, Fukuda MJ, Neves FH, Carmona MJ, et al. Computed tomography assessment of lung structure in patients undergoing cardiac surgery with cardiopulmonary bypass. Brazilian J Med Biol Res. 2011;44(6):598-605.

2. Diken ÖE, Diken AI, Yalçınkaya A, Özyalçın S and Hanedan MO. The predictive role of computed tomography on respiratory complications following coronary artery bypass surgery. J Clin Anal Med. 2018;9(5):402-6.

3. Younossian AB, Adler D, Bridevaux PO and Kherad O. Postoperative pulmonary complications: how to anticipate and prevent the risk? Rev Med Suisse. 2011;7(317):2214-6.

4. Sabaté S, Mazo V and Canet J. Predicting postoperative pulmonary complications: implications for outcomes and costs. Curr Opin Anesthesiol. 2014;27(2):201-9.

5. Hussain SMA and Harky A. Complications of coronary artery bypass grafting. Int $\mathbf{J}$ Med Rev. 2019;6(1):1-5.

6. Wynne R and Botti M. Postoperative pulmonary dysfunction in adults after cardiac surgery with cardiopulmonary bypass: clinical significance and implications for practice. Am J Crit care. 2004;13(5):384-93.

7. Jensen L and Yang L. Risk factors for postoperative pulmonary complications in coronary artery bypass graft surgery patients. Eur J Cardiovasc Nurs. 2007;6(3):241-6.
Sambol J, Klapholz M, et al. In-hospital outcomes and complications of coronary artery bypass grafting in the United States between 2008 and 2012. J Cardiothorac Vasc Anesth. 2017;31(1):19-25.

9. Kolff WJ, Effler DB, Groves LK, Hughes CR and McCormack LJ. Pulmonary complications of open-heart operations: their pathogenesis and avoidance. Cleve Clin Q. 1958;25(2):65-83.

10. Szeles TF, Yoshinaga EM, Alencar W, Brudniewski M, Ferreira FS, Auler Jr JOC, et al. Hypoxemia after myocardial revascularization: analysis of risk factors. Rev Bras Anestesiol. 2008;58(2):124-36.

11. Magnusson L, Zemgulis V, Wicky S, Tyden $\mathrm{H}$, Thelin $\mathrm{S}$ and Hedenstierna G. Atelectasis is a major cause of hypoxemia and shunt after cardiopulmonary bypass. Anesthesiol J Am Soc Anesthesiol. 1997;87(5):1153-63.

12. Hachenberg T, Brüssel T, Roos N, Lenzen H, Möllhoff T, Gockel B, et al. Gas exchange impairment and pulmonary densities after cardiac surgery. Acta Anaesthesiol Scand. 1992;36(8):800-5.

13. Tenling A, Hachenberg $\mathrm{T}$, Tyden $\mathrm{H}$, Wegenius $\mathrm{G}$ and Hedenstierna G. Atelectasis and gas exchange after cardiac surgery. Anesthesiol J Am Soc Anesthesiol. 1998;89(2):371-8.

To cite this article: Hesham M. Farouk, Ibrahim M. Helmy, Ahmed M. shalaan, Mona M. Rewisha. Thoracic Extra Cardiac Complications Detected in Patients after GABG at Multidetectorcomputed Tomography Coronary Angiography. BMFJ 2022; 39(Radiology): 89-97. DOI: 10.21608/bmfj.2021.19468.1161 